\title{
Microcephalic osteodysplastic primordial dwarfism type II
}

INSERM

\section{Source}

INSERM. (1999). Orphanet: an online rare disease and orphan drug data base. Microcephalic osteodysplastic primordial dwarfism type II. ORPHA:2637

'Microcephalic osteodysplastic primordial dwarfism type II (MOPDII) is a form of microcephalic primordial dwarfism (MPD; see this term) characterized by severe pre- and postnatal growth retardation, with marked microcephaly in proportion to body size, skeletal dysplasia, abnormal dentition, insulin resistance, and increased risk for cerebrovascular disease.' 